\title{
因HAD
}

ISSN-L: 2530-5115

DOI: http://doi.org/10.22585/hospdomic.v2i1.39

\section{Reseña de libro: Revistas científicas: Situación actual $y$ retos de futuro}

Book review: Scientific journals: Current situation and future challenges

\section{Helena Martín-Rodero}

Biblioteca, Facultad de Medicina, Universidad de Salamanca, Salamanca, España.

Correspondencia/Correspondence

Helena Martín-Rodero

helena@usal.es

Conflicto de Intereses/Competing interest

No existe ningún conflicto de interés en el presente estudio

Ficha editorial

- Título: Revistas científicas: Situación actual y retos de futuro

- Editor: Ernest Abadal

- Editorial: Edicions de la Universitat de Barcelona

- Número de páginas: 276

- ISBN: 978-84-9168-004-8

- Copyright (C) Edicions de la Universitat de Barcelona

- Este documento está sujeto a la licencia de

Reconocimiento-NoComercial-SinObraDerivada de Creative Commons

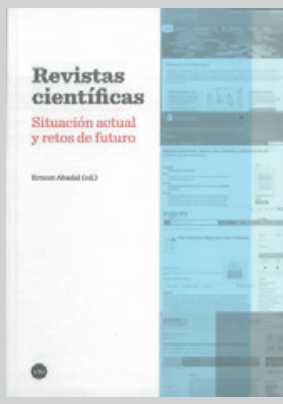

CÓMO CITAR ESTE TRABAJO | HOW TO CITE THIS PAPER

Martin-Rodero H. Reseña de libro: Revistas científicas: Situación actual y retos de futuro. Hosp Domic. $2018 ; 2(1): 31-5$ 
El libro que aquí presentamos, publicado por la Universitat de Barcelona, constituye una excelente contribución al debate suscitado, en los últimos tiempos, sobre el futuro de las revistas científicas.

Se trata de una completísima obra que ofrece a los lectores una amplia panorámica sobre el tema, construida a partir de las diferentes perspectivas y enfoques ofrecidos por los autores.

El contenido se estructura en tres grandes secciones y once capítulos. Comienza con un prólogo de Mikael Laakso que, aunque correcto, no deja ver del todo en sus líneas la excelente obra que anticipa. Le sigue una presentación del editor Ernest Abadal, y finaliza con las notas biográficas de los expertos que han hecho posible esta monografía.

La primera sección, la más general y amplia, es introducida por Ángel Borrego que realiza un recorrido histórico desde la aparición de las revistas científicas, como principal medio de comunicación de la ciencia, hasta la actualidad. Sin duda, este primer capítulo sirve de marco ideal para el desarrollo de los capítulos que vienen a continuación.

Miguel Navas muestra la evolución de las revistas científicas a nivel internacional, ofreciendo datos sobre los países que concentran una mayor producción de títulos, la situación de los llamados países emergentes o la actividad de la llamados países periféricos; sobre cómo se distribuyen las revistas por campos de investigación y por idiomas. Asimismo, analiza las principales bases de datos, tanto las de carácter más 'global' como algunas de las bases de datos alternativas de cobertura nacional y regional, para finalmente pasar a describir cuál es la situación actual y la naturaleza de las editoriales.

Francisca Abad aborda el sistema de revisión por pares como pilar fundamental de los procesos de comunicación científica, haciendo un análisis detallado de los sistemas de revisión desde sus orígenes hasta el momento actual. Señala cuáles son las características generales, beneficios, críticas y principales limitaciones de los 'modelos tradicionales'. Asimismo describe los nuevos sistemas de revisión por pares surgidos para mejorar o al menos complementar los ya existentes.

Emilio Delgado realiza un repaso de los criterios y métodos empleados para evaluar las revistas científicas. Pone de manifiesto que la evaluación de las revistas es multidimensional y que sus medidas no tienen un carácter absoluto y objetivo. En este sentido, afirma que lo que cabría esperar es que la evaluación de las revistas fuera multifacética, donde se tengan en consideración más variables, más indicadores y más fuentes.

Igualmente subraya la transformación que ha supuesto la irrupción del medio digital que ha favorecido la aparición de nuevas interacciones con los contenidos de las revistas y la presencia de nuevas variables e indicadores. La existencia de nuevas aplicaciones y nuevas plataformas de comunicación científica han propiciado el nacimiento de nuevas métricas que van a permitir valorar aisladamente los documentos y a los autores que los producen.

Completa esta primera sección Lluis Anglada con una revisión de los sistemas de compra de este tipo de publicaciones. Nos habla de lo que ha significado la transición de las revistas en papel al formato digital, de la oferta editorial de paquetes de revistas (Big Deals), de los consorcios de compras y de los cambios derivados del acceso abierto. Aunque todo apunta a que el acceso abierto será una realidad, no están todavía claros los mecanismos económicos que lo sustentarán. Iniciativas como SCOAP3 pueden ser una solución. El autor dibuja, no obstante, un futuro incierto, donde las bibliotecas deben seguir siendo las facilitadoras de información y han de ayudar a potenciar la publicación en abierto.

La segunda parte de la obra está dedicada, de manera especial, a la situación de las revistas científicas en España. Remedios Melero, a partir de los datos que ofrece la base de datos Dulcinea, realiza un estudio de la situación actual de las revistas españolas, describiendo cuál es el perfil de estas publicaciones en relación con las áreas disciplinares, el tipo de acceso en la web, la titularidad de los derechos de explotación o la reutilización de los contenidos.

Melba Claudio y Anna Villarroya ofrecen, a través de las encuestas realizadas a los editores de las revistas científicas españolas incluidas en la base de datos Dulcinea, un minucioso estudio económico de las mismas, que arroja como resultado la caracterización de los perfiles de las revistas españolas y 
la obtención de información sobre los procesos de la gestión editorial. Asimismo el estudio ha permitido identificar y analizar cuatro modelos de negocio comunes en el ámbito de la edición científica en España.

Por último, Marta Somoza, Javier Guallar, Josep-Manuel Rodríguez-Gairín y Ernest Abadal analizan la presencia de las revistas españolas en las bases de datos internacionales como criterio de calidad de las mismas.

El estudio considera tres grandes grupos de bases de datos en función de la relevancia otorgada por investigadores, universidades o agencias evaluadoras: a) Web of Science (WoS) y Scopus; b) Directory of open access journals (DOAJ); c) Bases de datos multidisciplinares y especializadas.

Los autores utilizaron los registros y herramientas de la base de datos MIAR (Matriz de Información para el Análisis de Revistas) para seleccionar las revistas etiquetadas como españolas en enero de 2017 (3.382 títulos).

La última sección se centra en los nuevos desarrollos y tendencias que van a definir la edición de las revistas científicas.

Ernest Abadal trata de la transformación que el modelo de acceso abierto ha supuesto en los procesos de comunicación científica y analiza cuáles son los principales retos que las revistas en acceso abierto deben afrontar en el momento actual: incrementar su crecimiento, superar el debate sobre sus niveles de calidad tratando de evitar 'la contaminación de las llamadas revistas depredadoras', consolidar las vías de financiación y lograr la sostenibilidad económica o impulsar el desarrollo y ampliación de políticas favorables al acceso abierto.

El penúltimo capítulo, a cargo de Candela Ollé y Alexander López-Borrull, está dedicado a las redes sociales y a la utilización de métricas complementarias, almetrics. Los autores ponen de manifiesto cómo las redes sociales han transformado el modelo de comunicación y las formas de relación entre los actores que intervienen en la generación del conocimiento y cómo éstas se han convertido en potentes herramientas de difusión y de construcción colaborativa del mismo. Describen seis redes sociales académicas y analizan su potencial utilidad para las revistas científicas.

En la segunda parte del capítulo los autores tratan de las almetrics como nuevos indicadores para medir el impacto y difusión de la ciencia, analizando sus características y reflexionando sobre las implicaciones y retos futuros.

El último capítulo firmado por Alexander López-Borrul está dedicado a los aspectos más innovadores adoptados por las revistas científicas: desde los megajournals a los data journals, o los nuevos modelos y formatos de artículos o las nanopublicaciones como unidades de información más pequeñas publicables. El autor abre camino a la reflexión sobre nuevos modelos de publicación científica encaminados a satisfacer los requerimientos ahora existentes en las revistas científicas.

En definitiva, nos encontramos ante una obra equilibrada, bien estructurada y desarrollada, escrita con un lenguaje directo, sencillo y claro que constituye, sin duda alguna, una referencia indispensable para editores, revisores, investigadores, bibliotecarios y estudiantes universitarios.

La publicación ha sido promovida por parte del proyecto de investigación «Acceso abierto a la ciencia en España». Está accesible en papel y también puede ser descargada desde el portal de Edicions de la Universitat de Barcelona [http://www.publicacions.ub.edu/ficha.aspx?cod=08744]. 